\title{
Design and construction of underwater pipelines crossings
}

\author{
Yuliya Ryltseva* \\ Moscow State University of Civil Engineering, Yaroslavskoe shosse, 26, Moscow, 129337, Russia
}

\begin{abstract}
The new territories exploration for housing construction and production facilities within the country and the increase in the export of hydrocarbons require the constant development and improvement of pipeline transport. There are often cases when the need for the pipeline network crossing by various obstacles is recognized as the only possible design solution and economically reasonable, among the most difficult of which there are water bodies. Natural and waste water, oil and petroleum products, and gas are transported by underwater pipelines crossings. Aiming at optimizing the design and construction of underwater pipeline crossings requires constant monitoring of the technologies, equipment, and materials offered by the modern market. The research methods were based on the review of current regulatory and technical documentation, modern scientific and periodicals, and security documents. A special feature of the underwater pipelines crossings design is needed to predict the channel processes for the entire estimated period of their use. Underwater crossings construction is made by the trench and trenchless methods. The latter ones, which are currently the most popular, imply the following main types: horizontal directional drilling, directional drilling, tunneling, microtunneling. The construction technology choice is determined by the topographical features of the water body bottom, its hydrological characteristics, the geology of the construction site, the required length, the diameter of the pipeline network, and the features of the surrounding area as a whole. The results of the review study may be of interest for the specialists in the field of pipeline transport.
\end{abstract}

\section{Introduction}

There is a need for the construction of such structures as underwater crossings for pipelines to cross water barriers (watercourses, reservoirs). Underwater crossings are made at water supply, sewerage, gas supply networks and pipelines transporting hydrocarbons, and are characterized, as a rule, by special design and construction difficulties. The purpose of the study is to review and analyze the methods and means of constructing underwater pipelines crossings and to make a comparative analysis of the most optimal technologies. The relevance of the survey study is caused by the state of the main pipelines, which are currently in use in Russia: more than $50 \%$ of the total length of the pipeline networks are at the stage of the technical «obsolescence», that means that they require major repair in the near future, a number of objects require re-laying due to the changes in the direction of transport movement, changes in economic policy.

\footnotetext{
*Corresponding author: yuliya.ryltseva@mail.ru
} 


\section{Methods}

The object of the review study is the design and construction processes of underwater pipeline crossings. A review of current regulatory and technical documentation regulating the rules for the construction of underwater pipelines crossings, Russian and foreign scientific papers, periodicals (published over the past ten years), patents, information provided on the websites of companies offering services for the construction of underwater crossings is conducted in order to highlight the status of these issues. The collected information is summarized, analyzed and systematized.

\section{Results}

The requirements for the installation of water and sewer pipelines through water barriers are established by code of rules [SP 31.13330.2012 Set of rules. Water supply. Pipelines and portable water treatment plants; SP 32.13330.2018 Set of rules. Sewerage. Pipelines and wastewater treatment plants]. There are departmental norms, codes of rules in relation to the construction of gas and oil product pipelines crossing water barriers currently on the territory of the Russian Federation [VSN 010-88 Departmental building codes. Construction of main pipelines. Underwater crossings; SP 36.13330.2012 Set of rules. Trunk pipelines]. Under the design and construction of underwater pipelines crossings, as a rule, the increased control is performed, since the cost of repairing such structures in the most cases is equal to the cost of new construction [1]. As a whole, the modern technologies for the underwater crossings construction can be divided into two groups: trench and trenchless.

Under implementing trench methods the following methods of laying pipelines are used: pulling pipeline sections along the bottom of the trench, free immersion of pipes to the bottom from the surface of the reservoir, laying from pipe-laying vessels, immersion of pipes using floating cranes. The choice of the laying pipelines method in the trench is determined taking into account the topographic, hydrological conditions of the area, the hydraulic regime of the site where the pipeline is supposed to be placed, the parameters of the pipes (diameter, weight, length). Performing work by the trench method requires the organization of ballasting of the installed pipeline network, which can be carried out with the use of weights made of heavy concrete or cast iron, or reinforced concrete coatings applied to the pipe in the factory. In the study [2] the trench method of underwater crossings construction is noted to have a number of significant drawbacks, consisting in changing the shape and parameters of river channels (which, in turn, entails landscape changes in the coastal territory), the destruction of wintering pits of valuable fish species, the use of bulky loads and coatings that significantly complicate the construction process, the need for recultivation of the coastal territory after installation work, etc. Especially unfavorable consequences of the construction of underwater pipeline crossings are for shallow watercourses (up to $2 \mathrm{~m}$ deep), the channels of which are often not restored after the performed work. Changing the bottom geometry of such watercourses inevitably leads to the violation of the water regime, which, in turn, can lead to such adverse environmental consequences as waterlogging of the territory, overgrowth of the banks, the flora and fauna impoverishment of the water area.

The trenchless methods of underwater crossings construction are recognized as more environmentally friendly, since in this case, the negative impact on the watercourse bed and the bottom of the reservoir is completely excluded; there is no need for diving operations to survey the bottom. In addition, with regard to pipelines laid by trenchless technologies, the possibility of their exposure during the erosion of the channel, and, consequently, the possibility of damage and violation of insulation, are almost completely excluded. The authors [2] also point at a huge economic effect in relation to the construction of underwater pipelines crossings by trenchless methods and caused by a significant reduction in 
construction time among others. The most important disadvantage of trenchless methods is the need to invest considerable sums to purchase the required equipment. Trenchless technologies include the following types of methods: directional drilling (horizontal, inclined), microtunneling, tunneling.

The horizontal directional drilling (HDD) method is considered to be one of the first methods of trenchless pipes laying. Its production (described in detail in [3]) includes the following main operations:

1.Preparatory work consists in the delivery and installation of the necessary equipment to the territory of the construction work, verification of the angle of inclination of the drilling rig, trial start-up of mechanisms and of drilling mud preparation;

2.Pilot drilling consists in drilling a small diameter borehole along the entire length of the route with the supply of drilling mud to the drill string;

3. Borehole expansion is made by a reamer, the diameter of which exceeds not less than 1.5 times the diameter of the pipeline network;

4. Preparation of the borehole for pipeline pulling consists in pumping out the drilling fluid;

5.Pipeline network joint.

The HDD method (Figure1) is not recommended for use in friable and water-saturated soils, monolithic rocks $[4,5]$.

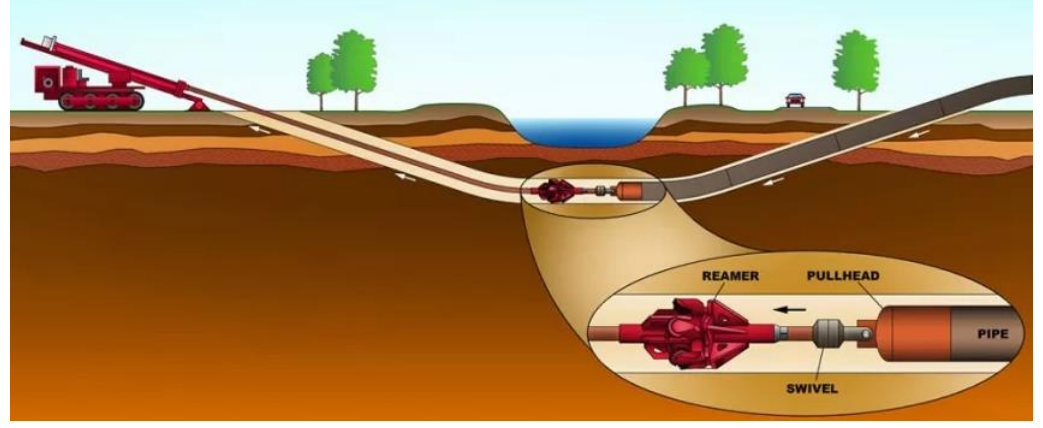

Fig. 1. Scheme of an underwater pipeline crossing laying by the HDD method (photo from open sources).

Using the HDD technologies, the quite complex tasks for laying underwater pipeline crossings are currently being solved. The construction of pipelines for water supply, sewerage, and gas supply by the HDD method on the territory of the Russian Federation is regulated by a separate code of rules [SP 341.1325800.2017 Set of rules. Underground engineering communications. Lining of by a method of the horizontal directional drilling]. The method ensures that the work is carried out within a short period of time, preserving the appearance of coastal zones (which is especially important for the embankments of large cities, which are a significant socio-cultural object). In the study [6] the unique Russian experience of construction of an underwater water pipeline crossing (two strings of polyethylene pipes with a diameter of $1000 \mathrm{~mm}$, length of $1.35 \mathrm{~km}$, laid $20 \mathrm{~m}$ below the level of the watercourse bottom) to Vasilievsky Island, located in the Neva River delta, is described.

In the first quarter of 2021, the cost of installation works for laying water supply and sewerage pipelines, using the HDD method through artificial or natural barriers, offered by the Russian construction companies was analyzed. The results of the averaged data are presented in Table 1. 
Table 1. The average cost of installation work pipelines laying, using the HDD method (price level for the first quarter of 2021).

\begin{tabular}{|c|c|c|}
\hline \multirow{2}{*}{$\begin{array}{c}\text { Nominal diameter of the pipe, } \\
\mathrm{mm}\end{array}$} & \multicolumn{2}{|c|}{$\begin{array}{c}\text { Average cost of installation work, RUB/1 m, with the total } \\
\text { length of the pipeline, } \mathrm{m}\end{array}$} \\
\cline { 2 - 3 } & up to $500 \mathrm{~m}$ & more than $500 \mathrm{~m}$ \\
\hline 50 & 1000 & 1500 \\
\hline 100 & 1800 & 1800 \\
\hline 150 & 2000 & 2500 \\
\hline 200 & 3000 & 4000 \\
\hline 300 & 4500 & 5500 \\
\hline 450 & 6000 & 900 \\
\hline
\end{tabular}

Horizontal directional drilling is a prototype of directional drilling (DD). DD is a more technologically complex process, the cost of which is slightly higher than the HDD method. For the first time in the USSR, the DD method was used in the 30s of the twentieth century to cross existing railways and highways with engineering communications, and in 1996, the first large-scale project was implemented to build an underwater crossing (a gas pipeline with a diameter of $1000 \mathrm{~mm}$, a length of $400 \mathrm{~m}$ ) through the Korzhenets River [1]. The DD method has the following limitations: complex geological conditions (pebbly, muddy and rocky soils, boulders), a large length of the water body along the intersection line, the diameter of the pipeline network [2]. In the study [7] it is reported that a fairly common problem in the construction of a pipeline network by the DD method is the deviation of the borehole (pipeline axis) from the design position. This is a consequence of the shedding of soil from the borehole arch, the formation of barriers (dunes) from large fractions (fragments) of soil that were not removed from the borehole during drilling, technological violations that consists in the non-compliance of the drilling tool used with the geological conditions of the construction site and (or) the low efficiency of the drilling mud used for cementing soil particles on the walls of the borehole. The scientists [7] recommend to use the specialized software products to assess the readiness of the borehole for pulling the pipeline network, which allows obtaining a geometric model of the borehole in the 2D format in the form of a longitudinal profile and in the 3D model format based on inclinometry data (the process of determining the location of the borehole in space). Such technologies automatically approximate the marks of the arch and the lower forming borehole recorded during inclinometry, and they estimate the likely stress-strain states of the pipeline when it is laid. In the studies described by the scientists [7] the software OpenFOAM (Great Britain) with the application ParaView has been used, the inclinometers of Russian production are distinguished as the magnetometric inclinometers - Quartz-32.03, IMMN 60-120, IMN-N76, IMNK-36 and gyroscopic ones - IGM 73 M, UGI-42, MIG-42, IGM-36S. The authors [1] recommend to limit the possibility of using the directional drilling method by rivers with a limited meandering, side-bed and belt-ridge type of channel processes.

Microtunneling is a trenchless automated method of laying pipelines, which consists in pushing the pipe into the soil by jacking stations (Figure 2). Using this method according to [2], the depth of pipeline network laying can be up to $30 \mathrm{~m}$. The advantages of this method are: a high level of automation of the process, high speed of work $(10-15 \mathrm{~m}$ of the pipeline network per day), high accuracy of construction in comparison with the project, the possibility of using the method in the difficult geological conditions (including in rocky soils) [5]. The maximum length of the pipeline network constructed by microtunneling can reach $500 \mathrm{~m}$. The trenchless pipeline construction technology Direct Pipe has now become worldwide popular, developed by the German company Herrenknecht AG. The method is similar to microtunneling, but it also has its own features (Figure 3). Direct Pipe is a onestage pipeline laying technology that requires only one work site (pit) for the installation of the network. Unlike microtunneling technology Direct Pipe allows to lay pipeline networks 
with a length of more than $1 \mathrm{~km}$, which makes it the most preferable when crossing sea barriers. The data on the cost of installation work for laying pipelines by microtunneling offered by Russian companies are presented in Table 2 .

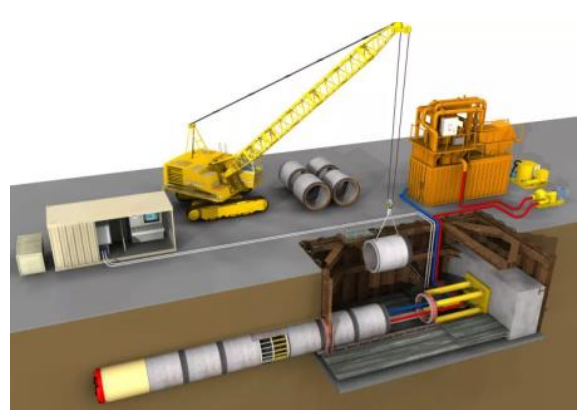

Fig. 2. The scheme of laying the pipeline network by microtunneling (photo from open sources).

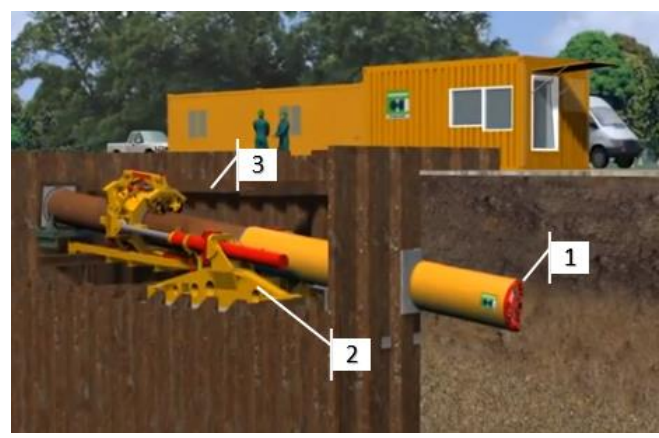

Fig. 3. The scheme of laying the pipeline network by the Direct Pipe method: 1 - main working (drilling) body; 2 - pipe thruster; 3 - working site (a pit).

Table 2. The average cost of installation work for laying pipelines by microtunneling.

\begin{tabular}{|c|c|c|}
\hline \multirow{2}{*}{$\begin{array}{c}\text { Nominal diameter of the pipe, } \\
\mathrm{mm} / \text { material }\end{array}$} & $\begin{array}{c}\text { Average cost of installation work, RUB/1 m, for the total length } \\
\text { of the pipeline, } \mathrm{m}\end{array}$ \\
\cline { 2 - 3 } & up to $200 \mathrm{~m}$ & more than $200 \mathrm{~m}$ \\
\hline $1000 /$ reinforced concrete & 52000 & 49000 \\
\hline $1200 /$ steel & 54000 & 52000 \\
\hline $1200 /$ reinforced concrete & 52000 & 50000 \\
\hline $1400 /$ steel & 54000 & 52000 \\
\hline $1500 /$ reinforced concrete & 62000 & 59000 \\
\hline $1700 /$ steel & 66000 & 63000 \\
\hline $2000 /$ reinforced concrete & 157000 & 149000 \\
\hline
\end{tabular}

Tunneling is a shield method of penetrating the protective casing-lining in the soil, carried out using shield jacks. This method is used in the construction of pipeline routes with a length of up to $10 \mathrm{~km}$ and a diameter of up to $3000 \mathrm{~mm}$. The disadvantage of this method is the probability of formation of karst cavities after construction work [2].

In the study $[8,9]$ it is noted that in the underwater pipelines crossings during usage, stresses may occur that exceed the calculated values. The reason for this is the residual stresses that arise as a result of: inconsistency in the trench profile of the welded pipeline configuration (most typical for curved sections of pipelines), uneven soil precipitation, heterogeneous soil load (because of the difference in density) exerted on the pipeline. When the pressure of the transport and temperature differ, the residual stresses add up to the operating stresses, which leads to an increase in the stress-strain state of the pipeline network $[10,11]$. This, in turn, can contribute to the occurrence of stress-corrosion cracks and rupture of welded joints. The described experience should be reflected at the stage of calculating the strength of underwater pipeline crossings.

The channel processes, in particular, an increase in the flow rate of the watercourse and, as a result, the erosion of its bottom, have a significant impact on the period of trouble-free use of underwater pipeline crossings $[12,13]$. That is why the modeling of channel processes is an integral stage of the design of underwater crossings. Based on this model, the designer can calculate the optimal depth of the pipeline, develop a plan for bottom and shore protection works. Currently, two types of modeling are used [14]: physical and mathematical. The physical model is based on the creation of a laboratory model of a water body. The created 
model should provide such hydraulic, morphometric and morphological characteristics of the flow that are similar to a natural water object. Based on this similarity, the data recorded in laboratory experiments are recalculated in relation to the real object. Mathematical modeling of riverbed processes is based on obtaining information about an object by creating and solving numerical problems. In the study [15] the significance of the methods of mathematical modeling is noted. They are developed by State Hydrological Institute (SHI), Russian Academy of Sciences (RAS) and Russian State Hydrometeorological University (RSHMU) during the new construction and reconstruction of underwater crossings of main pipelines. For automated modeling and long-term forecasting of riverbed processes Russian software (STREAM_2D [16], Unicom_Pro, CARDINAL) and foreign software (Mike 11, Mike 21, HEC-RAS, Delft 3D, Flo-2D) is also widely used today.

Considerable attention is given to anticorrosive and electrochemical protection in the construction of underwater pipelines crossings made of steel pipes [17], [SP 72.13330.2016 Set of rules. Protection of buildings, facilities and structures against corrosion]. The insulation coating of such pipes must have a high physical and chemical resistance to the environmental influences. In some cases, in particular, in the construction of pipeline crossings by the DD method in soils with a large number of abrasive inclusions, an additional reinforced coating is recommended, which eliminates damage to the main insulation.

In recent years, Russian scientists have proposed certain innovations in the construction of underwater pipelines. So, in the paper [18] an underwater crossing is described, the channel part of which is made in the form of an arc in the horizontal plane (Figure 4), the bulge of which is directed against the flow of water. The utility model provides effective resistance of a blurred section of the pipeline network to the hydrodynamic effect of water, and, consequently, an increase in the period of trouble-free use. The invention of the underwater crossing «Zero buoyancy» is of interest [19], assuming the laying of a pipeline network along the bottom of a water body without sinking. A special feature of the crossing is the presence of concrete blocks with liners for the pipelines crossings, the installation of which is intended to be on a crushed stone base (Figure 4). The proposed design has a number of advantages in comparison with its analogues: concrete blocks prevent the pipeline from floating up, the crushed stone base protects the crossing from seismic impact, the possibility of using the invention in weak silty soils. The authors [20] have proposed a model of an underwater pipeline crossing, which involves laying a network in a case. The pipeline itself must be made of flexible steel or polyethylene pipes (depending on the operating pressure of the transport medium). A special feature of the crossing is the existence of pressure sensors inside the case, which allow detecting quickly the presence and location of leaks from the pipeline (Figure 5).

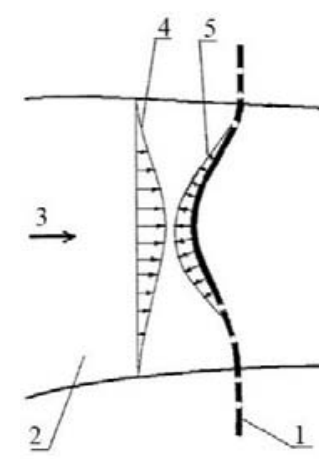

Fig. 4. Underwater crossing «Zero buoyancy» (cross section) [18]: 1 - pipeline pulling tunnel; 2 mass concrete; 3 - crushed-stone base; 4 - blocks-formwork. 


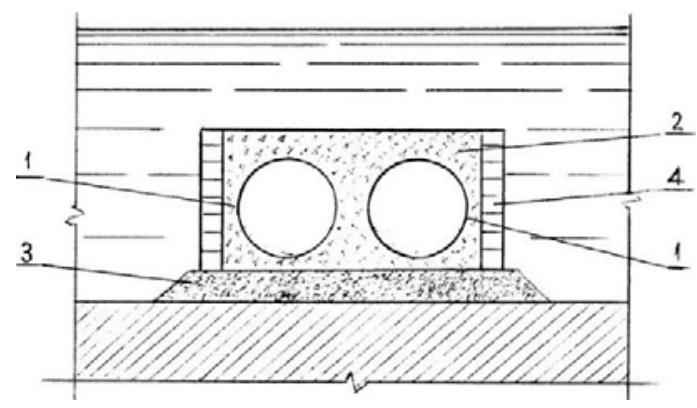

Fig. 5. River underwater pipeline crossing [19]: 1 - pipeline; 2 - river; 3 - river flow direction; 4 pressure patterns (of water flow and pipe resistances respectively).

\section{Conclusions}

Underwater pipeline crossings are an integral part of pipeline transport. They can be considered the most important elements of water and hydrocarbon transportation systems, since the violations committed at the design and / or construction stage can significantly reduce the period of trouble-free use of the object and negatively affect the ecology of the area. An integral stage in the design of underwater crossings is the modeling of channel processes, which allows calculating the optimal depth of the pipeline network, choosing effective methods and means to strengthen the bottom and banks of the water body. Currently, special software systems of Russian and foreign production are widely used for long-term forecasting of riverbed processes. Trenchless technologies are currently considered to be the most optimal way to build underwater pipeline crossings. A special feature of the construction of underwater pipeline crossings is the careful control of all stages of work, since even the slightest deviations from the project can lead to the significant material costs connected with the elimination of errors, improper operation of the system as a whole, the occurrence of stress-strain states in the pipeline network during construction and use. The timing and costs of the construction of underwater pipeline crossings are mainly determined by the degree of modern technologies and materials application in the design and installation process.

The significance of the research results is revealed in the modern methods description of design and construction of pipelines crossing water barriers, comparison and analysis of the technologies used, and the possibility of using the provided information by specialists in the field of pipeline transport.

\section{References}

1. Yu. Shakirova, A. Palaev. Underwater pipeline transmission through a water distance by an inclined directional drilling method. J. Eurasian Union of Scientists. 5(74), 57-63 (2020)

2. A. Sim, O. Erkovich. Ensuring ecological safety under construction of underwater crossings of main oil pipelines. J. Far East: problems of development of the architectural and construction complex. 1(1), 345-348 (2019)

3. A. Rogatkin. Application of horizontal directional drilling for laying water pipes. J. Improvement of methods of hydraulic calculations of culverts and sewage treatment plants. 1(45), 108-112 (2020)

4. A. Rybakov. Fundamentals of trenchless technologies (Press Bureau, Moscow, 2005) 
5. S. Ivannik, T. Gallyamov, F. Gafulov. Analysis of oil and gas pipelines tube-free installation methods through obstacles. Direct pipe technology. J. Synergy of Sciences. 48, 375-381 (2020)

6. I. Shelkov. Unique underwater crossing in St. Petersburg. J. Polymer pipes. 4(42), 74-75 (2013)

7. Z. Sharafutdinov, S. Urmancheev, R. Kapaev. Assessment the readiness of the well for pipeline during the construction of underwater crossing. J. Science and technology of pipeline transport of oil and petroleum products. 10(5), 470-478 (2020)

8. I. Gimazetdinov, V. Klimov, A. Gumerov. Peculiarities of river and ravines crossing pipelines stress state. J. Problems of collecting, preparing and transporting oil and petroleum products. 3(97), 55-65 (2014)

9. L. Chen, E.Arzaghi, M. Mahdi, V. Garaniya, R. Abbassi. Condition monitoring of subsea pipelines considering stress observation and structural deterioration. J. Journal of Loss Prevention in the Process Industries. 15, 178-185 (2018). DOI: 10.1016/j.jlp.2017.12.006

10. L. Muraveva, I. Ovchinnikov. Fatigue behavior of high-strenght steel-pipe in offshore pipeline. J. Vestnik MGSU. 13(10), 1260-1268 (2018)

11. L. Muravieva, I. Ovchinnikov. Problems of simulating subsea pipeline condition of the arctic shelf under seismic impact. J. Vestnik MGSU. 14(11), 1456-1465 (2019)

12. A. Khodzinskaya, V. Zommer. Hydraulic studies of bottom regulatory devices. J. Vestnik MGSU. 14(4), 464-472 (2019)

13. S.A. Makhnatov. Fresh approach to karst management in designing submerged pipeline crossings over large transit rivers. J. Vestnik MGSU. 11, 32-47 (2016)

14. D. Shatalov, D. Vafin. Forecast and modeling the impact evolution of river mechanics on the underwater crossings of main pipelines. J. Science and technology of pipeline transport of oil and petroleum products. 7(6), 44-53 (2017)

15. T. Rykova, D. Kazakov. Long-term forecasting of runoff characteristics by mathematical modeling of hydrological processes. J. Science and technology of pipeline transport of oil and petroleum products. 10(4), 352-363 (2020)

16. A. Aleksyuk, V. Belikov. Complex for calculating currents, bottom deformations, and pollution transport in open streams: Patent of the Russian Federation No. 2017617252 (2017)

17. I. Razyapov, Anticorrosive protection of pipelines which used during the inclined directional drilling method. J. Development prospects of science in the modern world: proceedings of the XII International Scientific and Practical Conference. 24-33 (2018)

18. A. Filatov, I. Veliyulin and other. River underwater crossing of the pipeline: the Patent of the Russian Federation No. 97473 (2010)

19. Yu. Groznyj, «Zero buoyancy» underwater crossing: Patent of the Russian Federation No. 2697753 (2019)

20. R. Sultanov, A. Gumerov and other. Underwater crossing: RF Patent No. 77661 (2008) 